\title{
Successful implementation of ChicaEducation system for Oncology Residency Standardized Training
}

\section{Quan Yao}

Sichuan Cancer Hospital and Research Institute https://orcid.org/0000-0001-7559-3443

Hong Wu

Sichuan Cancer Hospital and Research Institute

\section{Lian Zou}

Sichuan Academy of Medical Sciences and Sichuan People's Hospital

\section{Haitao Lan}

Sichuan Academy of Medical Sciences and Sichuan People's Hospital

\section{Shuchun Luo}

Sichuan Academy of Medical Sciences and Sichuan People's Hospital

\section{Shun Lu}

Sichuan Cancer Hospital and Research Institute

\section{Xianfu Li}

Affiliated Hospital of North Sichuan Medical College

Jinyi Lang

Sichuan Cancer Hospital and Research Institute

Chuan Xu ( $\nabla$ xuchuan100@163.com )

https://orcid.org/0000-0002-5320-2277

\section{Research article}

Keywords: Virtual reality, Medical Education, Radiation Therapy, Residency Standardized Training

Posted Date: July 31st, 2019

DOl: https://doi.org/10.21203/rs.2.12216/v1

License: (c) (i) This work is licensed under a Creative Commons Attribution 4.0 International License. Read Full License 


\section{Abstract}

The ability to access knowledge and skills of radiation oncology is fundamental for oncology residency standardized training. This study evaluates whether or not the ChicaEducation system for oncology residency standardized training contributes to training radiation oncology medical students. As a virtual reality system for radiotherapy training, ChicaEducation system was successfully implemented. We compared the ChicaEducation system training module with a traditional training module. Whether the integration of ChicaEducation into medical teaching was intended to enhance students' autonomic learning and comprehensive analysis were also evaluated. The integration of ChicaEducation system into oncology residency standardized training was valuable compared to traditional training methods and could improve radiation oncology medical students' perceptions and understanding. ChicaEducation system training module was positive and could enhance radiation oncology medical students' level of confidence in radiation oncology. The role of ChicaEducation system training module in delivering an efficient quantity of oncology medical education was ascertained because of its ability to visualize conceptual information within a simulated clinical environment. ChicaEducation system may alleviate economic burdens in some hospitals and be used for training for doctors in rural areas.

\section{Introduction}

Radiation therapy (RT) plays a major role in the treatment of cancer, and nearly $70 \%$ of all cancer patients need to receive radiotherapy during the course of their disease. Therefore, there is an increasing need for radiotherapy services. A significant shortage of staff has been training involved in radiotherapy in many countries. Planning and implementing radiation therapy is a complex process, based on hightech software and hardware, and involving a wide range of staff such as physicians, physicists, and radiation therapists. To ensure the implementation of radiotherapy, the staff must understand essential anatomy and spatial relationships in the patient. With the development of radiotherapy techniques, teaching methods are constantly changing and improving. Before medical students enter into radiotherapy environments, they are expected to have an understanding of radiation oncology. Due to potential high risks in the process of radiotherapy, a high skill level training is crucial and essential. Furthermore, there are latent risks when patients and clinical data are directly used for training (Boejen \& Grau, 2011). So it is essential to solve the problems above. Virtual reality (VR) system has been built for medical teaching and learning (Dunkley, 1994; Stevens et al., 2005). The system can meet the specific medical, educational needs, such as medical research, simulating clinical learning environment. VR has also been established and used for radiation therapy (RT) education by simulating radiation therapy environment. Simulation can offer safe, interactive, learning environments for medical students (Bridge, Appleyard, Ward, Philips, \& Beavis, 2007; Chamunyonga et al., 2018; Su, Sung, Jiang, Sun, \& Wu, 2005). The system contains a lavish visual linear accelerator model and essential auxiliary equipment and provides a combination of graphics, sensory technology, and a physical hand-held pendant which enables users to interact actively (Jimenez \& Lewis, 2018). And the system loads simulated patients' computed tomography (CT) data and radiation treatment plans (Jimenez, Hansen, Juneja, \& Thwaites, 
2017). Medical students can see the simulated dose distributions in CT slices. Moreover, medical students can develop new radiation treatment plans personally and adjust plan parameters repeatedly and immediately. Before radiation treatment, a simulated patient could be operated and moved to the right site in the VR system according to the radiation treatment plan. When the plan is implementing, the simulated sound of the radiation beam can be heard. ChicaEducation system was implemented for RT students in China in 2016. Radiation oncology medical students had a better handle on fundamental RT concepts, better knowledge of anatomy, simple RT delivery techniques, and building of confidence (Leong, Herst, \& Kane, 2018). These advantages were attributed to students' hands-on ability and experience with virtual radiotherapy equipment. And students could discover, analyze, and solve problems without adversely affecting patients or equipment (Kane, 2018). However, ChicaEducation system's use in radiation oncology medical students is less well reported.

The ChicaEducation system was introduced into the University of Electronic Science and Technology of China in 2017. The purpose of this article is to report on the University of Electronic Science and Technology of China's initial experience with ChicaEducation system. We provide a description of ChicaEducation system that was incorporated into radiation oncology for oncology residency standardized training. And the efficiency of ChicaEducation system training module in oncology medical education was evaluated.

\section{Methods}

\section{Study design}

This study consisted of ChicaEducation system training module group and traditional training methods group, using survey instruments for data collection. Each group had 30 radiation oncology medical students. Students in the traditional training methods group did not receive ChicaEducation system training. And students in the ChicaEducation system training module group received ChicaEducation system training for two months.

\section{Master of Radiation Oncology at the University of Electronic Science and Technology of China}

The radiation oncology is offered as a 3-year postgraduate program, which prepares medical students for subsequent entry into clinical training (Residency Standardized Training). Traditionally, the radiation oncology has been undertaken using a combination of didactic lectures tutorial conducted at university, as well as tutorials, practices, and demonstrations conducted in RT departments under the supervision of clinical radiation oncology medical students. 


\section{Participants}

All 60 radiation oncology medical students at Cancer Hospital affiliated to the School of Medicine, the University of Electronic Science and Technology of China were invited to participate in this study in 2019. All students were the first year of Standardized Training of Residents. The age of all the students ranged from 23 to 25. Ethical approval was obtained from the ethics committee of the University of Electronic Science, and Technology of China, and participants gave written informed consent.

\section{ChicaEducation system}

This system was used to offer networked teaching and training opportunities for medical student education. The integration of ChicaEducation system could supplement classroom teaching and introduce oncology medical students to virtual radiation therapy environments. Three ChicaEducation system practical sessions were developed: (1) Virtual CT system, (2) Target delineation and radiation treatment planning system, and (3) Linear accelerator simulation system. The learning objectives for each of the sessions are listed in Table 1. In the "Virtual CT systems" practical session radiation oncology students can learn organs at risk in radiation therapy and how to delineate organs at risk accurately according to anatomies. Simulated CT datasets from different anatomical sites of bodies were imported into the ChicaEducation system. The CT data contained four anatomical structures: head and neck, thorax, abdomen, pelvis regions. In the "Target delineation and radiation treatment planning system" practical session radiation oncology students can obtain target delineation and radiation treatment plan of cancers at different sites. Primary and nodal gross tumor volumes (GTVs), and primary and nodal clinical target volumes (CTVs) can be delineated based on the simulated CT images. Many radiation treatment plan systems, including the Eclipse treatment planning system (Varian, California, USA) and the Pinnacle 3 treatment planning system (Philips, Best, Holland) were employed inChicaEducation system. The students can see many simulated radiation treatment plans in terms of different dose prescriptions. And the students can perform a radiation treatment plan independently. Through the ChicaEducation system, students' plans can be evaluated. A better plan can be chosen by comparing different plans. The

"Linear accelerator simulation system" practical session can provide an introduction to various quality control (QA) measurements. ChicaEducation system can offer linear accelerators in a life-sized virtual radiotherapy treatment room with immobilization equipment on the treatment couch. It is essential to introduce QA methods to radiation oncology medical students. QA workflows on teaching tools were offered in ChicaEducation system. Furthermore, the students can perform QA measurements independently in the ChicaEducation system.

\section{Student evaluation of ChicaEducation systems}

Evaluations of two group students were conducted using three questionnaires ("Virtual CT system" session, "Target delineation and radiation treatment planning system" session and "Linear accelerator 
simulation system" session). Sixty students participated in the evaluation, and 60 completed the three questionnaires were received. In the "Virtual CT system" session in table 3, all students were asked to rate their current knowledge on the relationship of anatomy to target delineation and radiation therapy. $\mathrm{A}$ score of each item was on a scale of $1-5$, with a score of 1 indicating poor and a score of five indicating excellent. In the "Target delineation and radiation treatment planning system" session, some questions were shown in table 4. Students reported that the "Target delineation and radiation treatment planning system" session helped them link the theoretical knowledge to target delineation and radiation treatment planning system. Some simple questions were listed in table 5 in the "Linear accelerator simulation system" session. These questions were asked about the role of physics of radiology course and validation of radiation treatment.

\section{Statistical Analysis}

Continuous variables were expressed as median and range. Statistical data were performed using SPSS 18.0 statistical software. Wilcoxon rank-sum tests were used for continuous variables that were not normally distributed. All tests of significance were two-sided, and the statistical difference was considered significant if P-values were $<0.05$.

\section{Results}

\section{ChicaEducation system}

Figure 1a showed screenshots from the "Virtual CT systems" practical session in the ChicaEducation system. The visualization tools in the ChicaEducation system were used to systematically describe the region of the head and neck, concerning the patient's external view (Fig 1b) and the internal anatomy shown as CT images (Fig 1C) and 3D volumes (Fig 1d).

Figure 2 showed screenshots from the "Target delineation and radiation treatment planning system" practical session in the ChicaEducation system. ChicaEducation system has included visualization of RT plans for a range of tumor sites, such as head and neck cancer, lung cancer, and prostate cancer. Examples from a patient irradiated for head and neck cancer were presented in Figure 2. Spatial modulation was achieved utilizing dynamic multileaf collimator (MLC) trajectories, which were synchronized to the gantry angle and dose rate. (Fig 2a) The dose volume histogram (DVH) of volumetric modulated arc radiotherapy (VMAT) plan was shown in Fig 2b. The VMAT plan was based on the applied CT volume, a simulated dose volume with the same resolution and extent as the CT volume. Dose values in RT were typically visualized with a rainbow color map mapping low dose to the blue scale of the rainbow and high dose to red $\mathbb{F i g} 2 \mathrm{c} \bigotimes$. Fig $2 \mathrm{~d}$ presented an electronic portal imaging devices (EPIDs) image frame was used as a function of gantry angle during clinical VMAT deliveries (Fig 2d). 
Figure 3 showed examples of screenshots from the "Linear accelerator simulation system" practical session in ChicaEducation system. The virtual water tank in ChicaEducation linear accelerator simulation system was displayed (Figure 3a), and it was used to create PDD plots. Multileaf collimators (MLCs) for the selected beam in ChicaEducation linear accelerator simulation system was shown in Figure $3 \mathrm{~b}$. ChicaEducation linear accelerator simulation system could monitor and calibrate the placement of radiotherapy. A sample of head and neck placement was displayed in Figure 3c, and Figure $3 \mathrm{~d}$ at different angles.

\section{Student evaluations}

Distribution of select participant characteristics was shown in table 2. There was no statistically significant difference in gender and age distribution between ChicaEducation system training module group and traditional training methods group $(P>0.05)$. In the "Virtual CT system" session, there was a statistically significant difference between the two groups in table 3 . Students reported higher evaluation scores in the questionnaire in ChicaEducation system training module group than traditional training methods group. ChicaEducation system training group students could better connect anatomy to radiation oncology theory. In the "Target delineation and radiation" session, there was also a statistically significant difference between the two groups except for the evaluation of "How would you rate your understanding of 3DCRT?" in table 4. Score statistics for each of the three statements were shown in table 5 in the "Linear accelerator simulation system" session. And there was a significant difference in evaluation scores in this session between the two groups. The evaluation scores were higher in learning in ChicaEducation system training module group than in traditional training methods group.

\section{Discussion}

VR is a new technology that has been widely used in medical education in recent years. VR is an interesting form of simulation and maybe better suit for the acquisition of both knowledge and skills (Davies \& Helmreich, 1997; Djukic, Mandic, \& Filipovic, 2013). Several studies have indicated the efficacy of VR in medical education for improving the clinical and procedural competence of learners compared with traditional teaching methods (Cook et al., 2013; Kane, 2018; McGaghie, Issenberg, Petrusa, \& Scalese, 2010). VR has become available for radiotherapy training, enabling medical students to learn the whole process of simulated radiation therapy without interfering with the clinical workflow. And students can repeatedly operate without the risk of making errors (Boejen \& Grau, 2011). Furthermore, instructors can make better assessments of their students' skills through VR tools (Mariani \& Pego-Fernandes, 2011).

ChicaEducation system is a VR tool that can provide training without involving patients and enable repetitive training. This paper describes our initial experience with the ChicaEducation system and introduction to ChicaEducation based practical sessions. The use of ChicaEducation system in an educational setting has several possible benefits to radiation oncology medical students. ChicaEducation systems training qualified medical students better than conventional training. It may improve knowledge 
and clinical skills of radiation oncology medical students. It is suggested that ChicaEducation system training remains to be used as a supplementary teaching method at the University of Electronic Science and Technology of China. Our results demonstrated that ChicaEducation system was a useful learning and training tool. As can be seen from the questionnaire, students have a higher interest in learning in ChicaEducation system training module group than that to traditional training methods group. The radiation oncology medical students received ChicaEducation system training had more enthusiasm for radiation oncology education. Their interests were also increased through ChicaEducation system. After ChicaEducation system training, the radiation oncology medical students quickly understood the complex process of radiation therapy. The ChicaEducation system also provided a detailed description of the process of simulated radiation therapy. Besides, the ChicaEducation system provided a more flexible way of teaching. As the ChicaEducation system was delivered into a classroom-based setting, students could operate repeatedly and gradually master the process of simulated radiation therapy and do not think about making mistakes. As a complementary training along with main training, ChicaEducation system training can never replace the traditional training in the real environment. However, there were some limitations to this study. The first one was a small sample size, which reduces the ability to generalize results to a greater population. Secondly, it was a one-time educational experience. In addition, the results of evaluation questionnaires are subjective. It was difficult to assess students' knowledge. Due to the difference in students' knowledge and skills, the bias may occur in the results that the students chose.

In conclusion, our experience with the ChicaEducation system in the radiation oncology medical education at the University of Electronic Science and Technology of China was efficient and demonstrates the viability of ChicaEducation system for radiation oncology medical student education. Integration of ChicaEducation system into the medical curriculum can be valuable in addition to the traditional methods. Further investigation should be conducted to ascertain ChicaEducation system's role in delivering efficient quantity and quality of radiation oncology medical student education.

\section{Declarations}

\section{Acknowledgments}

The authors acknowledge the contributions of the students and lecturers who participated in this study. This research was supported by the National Natural Science Foundation of China (Grant No. 81873048).

\section{Compliance with ethical standards}

All procedures performed in studies involving human participants were in accordance with the ethical standards of the University of Electronic Science and Technology of China. Informed consent was obtained from all individual participants included in the study. All data of questionnaires collected was anonymous. 


\section{Declaration of interest}

The authors declare that they have no conflict of interest.

\section{References}

Boejen, A., \& Grau, C. (2011). Virtual reality in radiation therapy training. Surg Oncol, 20(3), 185-188.

Bridge, P., Appleyard, R. M., Ward, J. W., Philips, R., \& Beavis, A. W. (2007). The development and evaluation of a virtual radiotherapy treatment machine using an immersive visualization environment. Comput Educ, 49(2), 481-494.

Chamunyonga, C., Burbery, J., Caldwell, P., Rutledge, P., Fielding, A., \& Crowe, S. (2018). Utilising the Virtual Environment for Radiotherapy Training System to Support Undergraduate Teaching of IMRT, VMAT, DCAT Treatment Planning, and QA Concepts. J Med Imaging Radiat Sci, 49(1), 31-38.

Cook, D. A., Hamstra, S. J., Brydges, R., Zendejas, B., Szostek, J. H., Wang, A. T., et al. (2013). Comparative effectiveness of instructional design features in simulation-based education: systematic review and meta-analysis. Med Teach, 35(1), e867-898.

Davies, J. M., \& Helmreich, R. L. (1997). Virtual reality in medical training. CMAJ, 157(10), 1352-1353.

Djukic, T., Mandic, V., \& Filipovic, N. (2013). Virtual reality aided visualization of fluid flow simulations with application in medical education and diagnostics. Comput Biol Med, 43(12), 2046-2052.

Dunkley, P. (1994). Virtual reality in medical training. Lancet, 343(8907), 1218.

Jimenez, Y. A., Hansen, C. R., Juneja, P., \& Thwaites, D. I. (2017). Successful implementation of Virtual Environment for Radiotherapy Training (VERT) in Medical Physics education: The University of Sydney's initial experience and recommendations. Australas Phys Eng Sci Med, 40(4), 909-916.

Jimenez, Y. A., \& Lewis, S. J. (2018). Radiation therapy patient education using VERT: combination of technology with human care. J Med Radiat Sci, 65(2), 158-162.

Kane, P. (2018). Simulation-based education: A narrative review of the use of VERT in radiation therapy education. J Med Radiat Sci, 65(2), 131-136.

Leong, A., Herst, P., \& Kane, P. (2018). VERT, a virtual clinical environment, enhances understanding of radiation therapy planning concepts. J Med Radiat Sci, 65(2), 97-105.

Mariani, A. W., \& Pego-Fernandes, P.M. (2011). Medical education: simulation and virtual reality. Sao Paulo Med J, 129(6), 369-370. 
McGaghie, W. C., Issenberg, S. B., Petrusa, E. R., \& Scalese, R. J. (2010). A critical review of simulationbased medical education research: 2003-2009. Med Educ, 44(1), 50-63.

Stevens, S. M., Goldsmith, T. E., Summers, K. L., Sherstyuk, A., Kihmm, K., Holten, J. R., et al. (2005). Virtual reality training improves students' knowledge structures of medical concepts. Stud Health Technol Inform, 111, 519-525.

Su, T. S., Sung, W. H., Jiang, C. F., Sun, S. P., \& Wu, C. J. (2005). The development of a VR-based treatment planning system for oncology. Conf Proc IEEE Eng Med Biol Soc, 6, 6104-6107.

\section{Tables}


Table 1 Learning objectives for "Virtual CT system", "RT treatment planning system" and "Linear accelerator simulation system" practical sessions

At the completion of the practical session, students should be able to:

Virtual CT systems

1. Identify the major organs in the head and neck, thorax, abdomen, pelvis

2. Describe the major organs in the head and neck, thorax, abdomen, pelvis, with relation to

(a) Their characteristics

(b) Relationship to other organs

(c) Organ specific cancers

(d) Treatment planning

(e) Treatment delivery

1. Describe the target delineation and radiation treatment planning system

2. Using a target delineation and treatment planning system

(a) Locate a simulation centre on a CT dataset

(b) Identify and contour GTV,CTV and organs at risk for a head and neck plan

(c) Contour a planning target volume (PTV)

(d) Produce a clinically acceptable parallel opposed head and neck plan

(e) Evaluate a RT plan

Linear accelerator simulation system

1. Identify and describe the function of an ion chamber, plotting tank, chamber calibration, QA plate and alignment phantom 
2. Using the ChicaEducation system

(a) Simulate radiotherapy simulation localization machine

(b) Simulate linear accelerator operation

(c) Simulate validation before treatment

(d) Simulate QA procession

Table 2 Distribution of selected participant characteristics

\begin{tabular}{cccccc}
\hline Characteristics & \multicolumn{2}{c}{ traditional training } & \multicolumn{2}{c}{$\begin{array}{c}\text { ChicaEducation system training module } \\
\text { group }\end{array}$} & P \\
& $\begin{array}{c}\text { methods group } \\
\text { Frequency }\end{array}$ & Percent & Frequency & Percent & \\
\hline Age (years) & 6 & 20.0 & 8 & 26.7 & 0.809 \\
23 & 19 & 63.3 & 18 & 60.0 & \\
24 & 5 & 16.6 & 4 & 13.3 & \\
25 & 16 & 53.3 & 17 & 56.7 & 0.795 \\
Gender & 14 & 46.7 & 13 & 43.3 & \\
Male & & & & & \\
Female & & & & & \\
\hline
\end{tabular}

Table 3 Questionnaires for the "Virtual CT system" practical session 


\begin{tabular}{|c|c|c|c|c|c|}
\hline & \multicolumn{2}{|c|}{$\begin{array}{l}\text { traditional } \\
\text { training } \\
\text { methods } \\
\text { group }\end{array}$} & \multicolumn{2}{|c|}{$\begin{array}{l}\text { ChicaEducation } \\
\text { system training } \\
\text { module group }\end{array}$} & \multirow[t]{2}{*}{$\mathrm{P}$} \\
\hline & median & range & median & range & \\
\hline $\begin{array}{l}\text { How would you rate your learning of } \\
\text { anatomical positions }\end{array}$ & 3 & $3-4$ & 4 & $4-5$ & 0.001 \\
\hline How would you rate the anatomy practical? & 3 & $2-4$ & 4 & $3-5$ & 0.013 \\
\hline $\begin{array}{l}\text { How useful were the CT images to your } \\
\text { understanding of anatomy? }\end{array}$ & 4 & 4-5 & 5 & $4-5$ & 0.021 \\
\hline $\begin{array}{l}\text { How would you rate your understanding of the } \\
\text { exterior and interior space relationships } \\
\text { between the organs }\end{array}$ & 3 & $3-4$ & 4 & $3-5$ & 0.001 \\
\hline $\begin{array}{l}\text { How well did you connect anatomy to } \\
\text { radiation oncology theory? }\end{array}$ & 3 & $2-5$ & 4 & $3-5$ & 0.006 \\
\hline
\end{tabular}

Table 4 Questionnaires for "Target delineation and radiation treatment planning system" practical session 


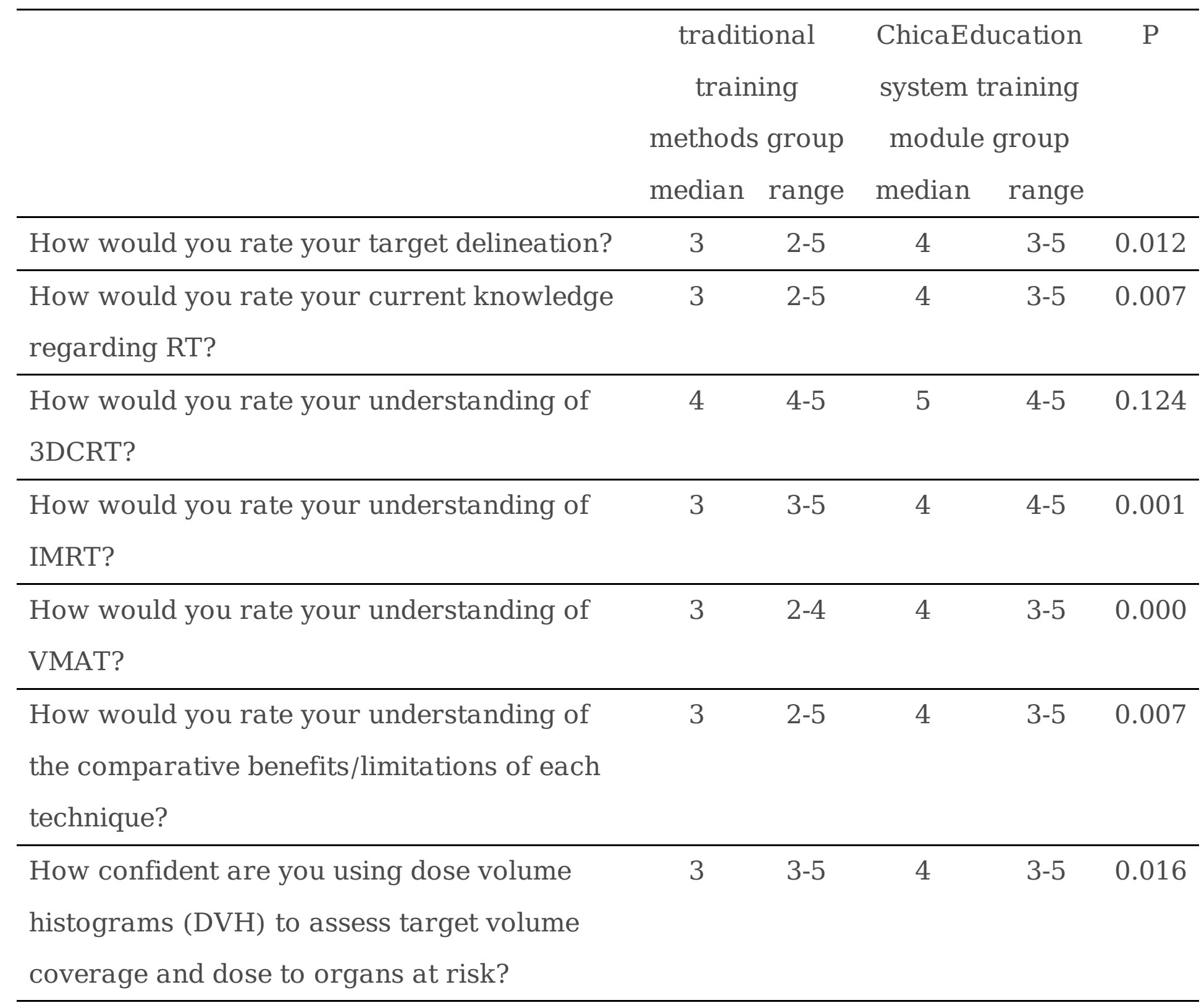

Table 5 Questionnaires for "Linear accelerator simulation system" practical session 


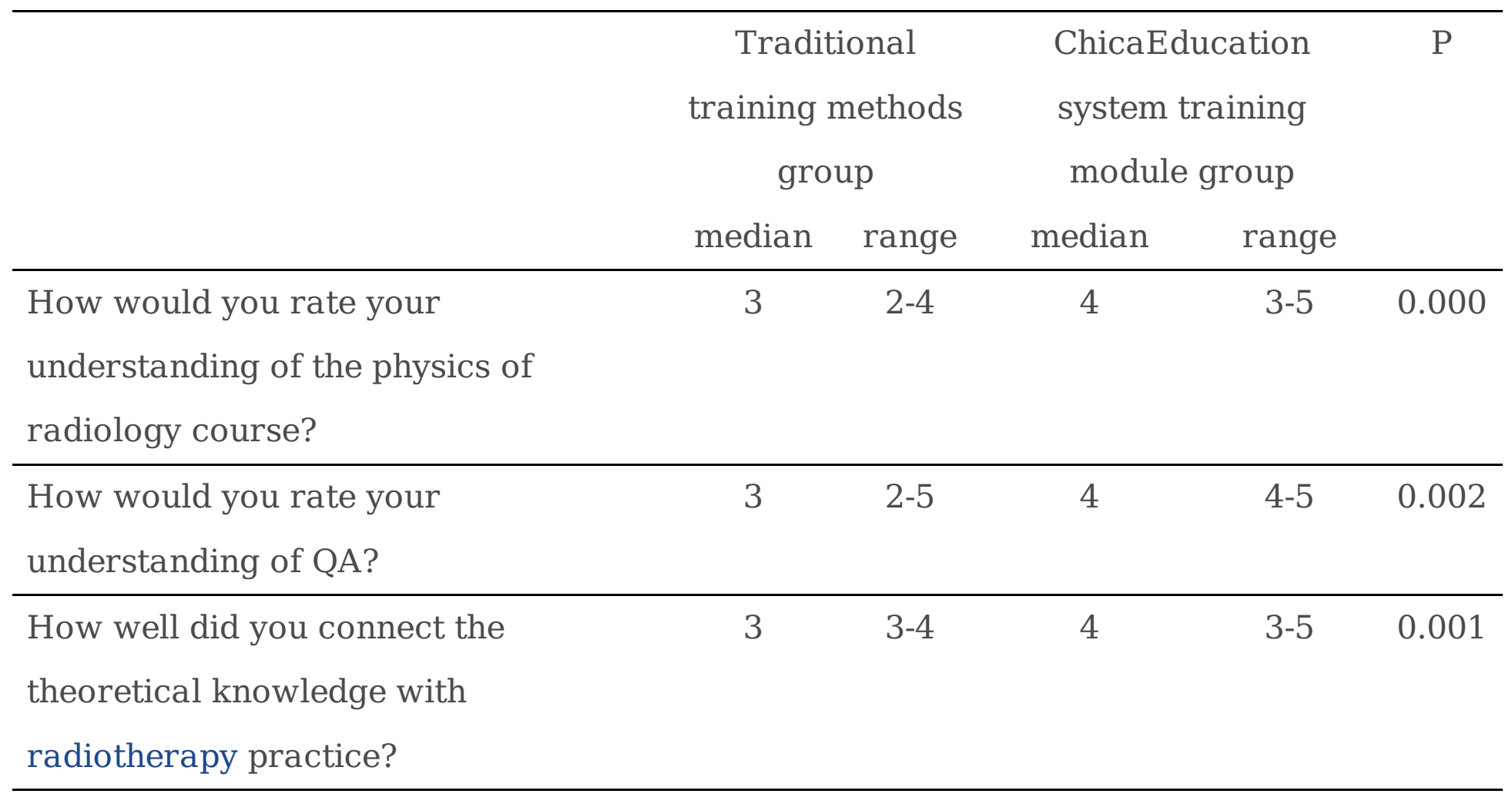

\section{Figures}



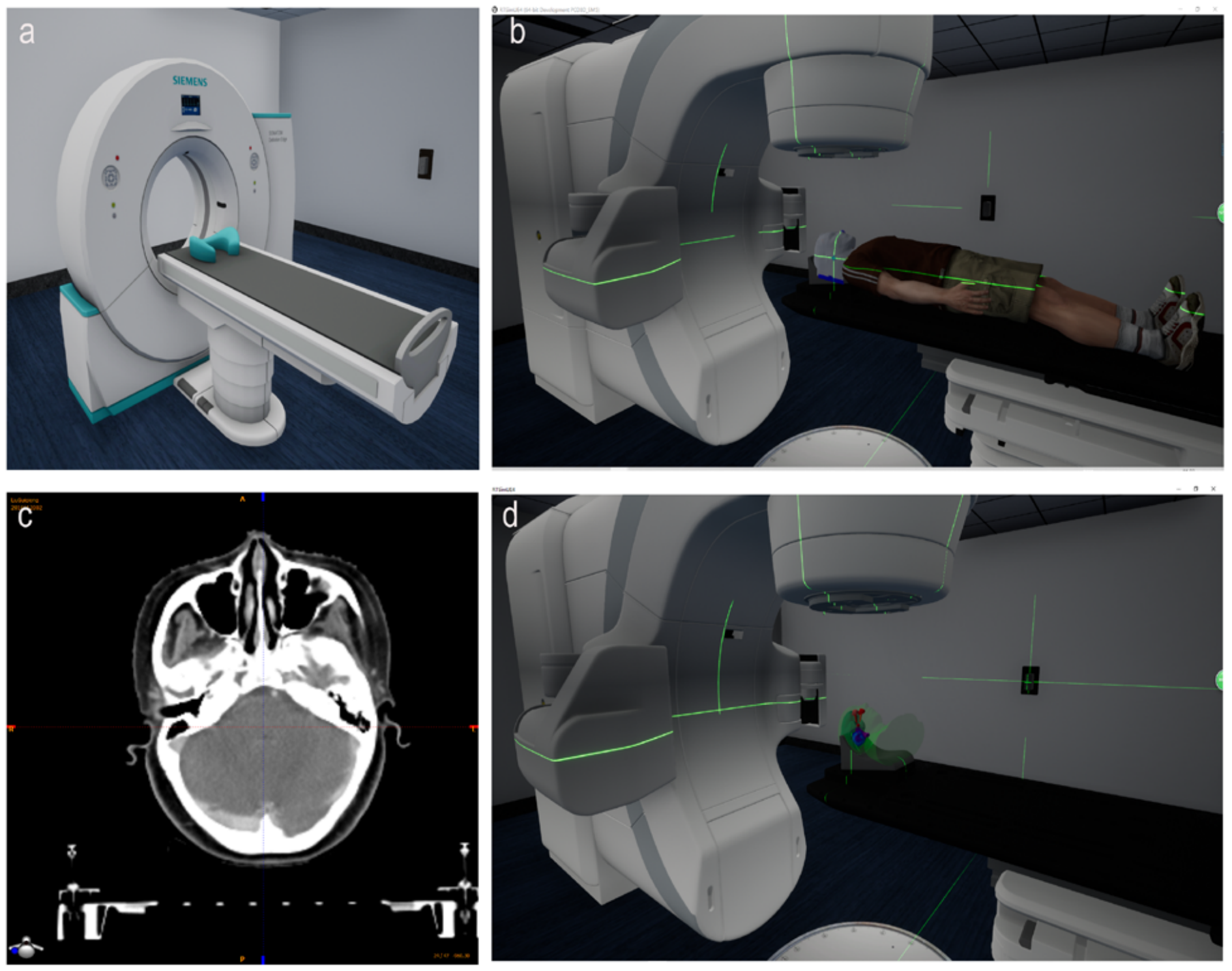

\section{Figure 1}

a showed screenshots from the "Virtual CT systems" practical session in the ChicaEducation system. The visualization tools in the ChicaEducation system were used to systematically describe the region of the head and neck, concerning the patient's external view (Fig 1b) and the internal anatomy shown as CT images (Fig 1C) and 3D volumes (Fig 1d). 

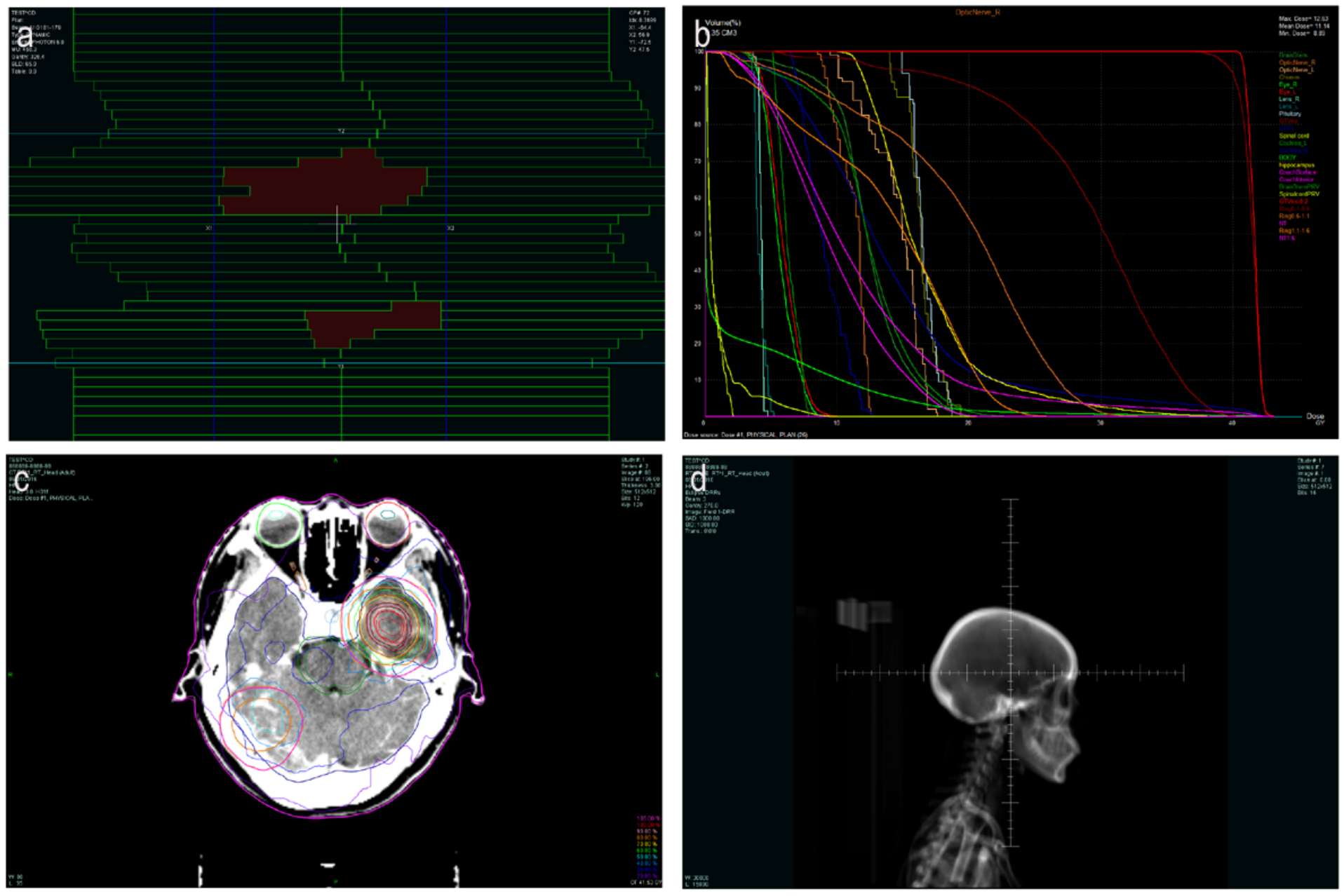

\section{Figure 2}

showed screenshots from the "Target delineation and radiation treatment planning system" practical session in the ChicaEducation system. ChicaEducation system has included visualization of RT plans for a range of tumor sites, such as head and neck cancer, lung cancer, and prostate cancer. Examples from a patient irradiated for head and neck cancer were presented in Figure 2. Spatial modulation was achieved utilizing dynamic multileaf collimator (MLC) trajectories, which were synchronized to the gantry angle and dose rate. (Fig 2a) The dose volume histogram (DVH) of volumetric modulated arc radiotherapy (VMAT) plan was shown in Fig 2b. The VMAT plan was based on the applied CT volume, a simulated dose volume with the same resolution and extent as the CT volume. Dose values in RT were typically visualized with a rainbow color map mapping low dose to the blue scale of the rainbow and high dose to red $\backslash F i g 2 c \rrbracket$. Fig $2 d$ presented an electronic portal imaging devices (EPIDs) image frame was used as a function of gantry angle during clinical VMAT deliveries (Fig 2d). 

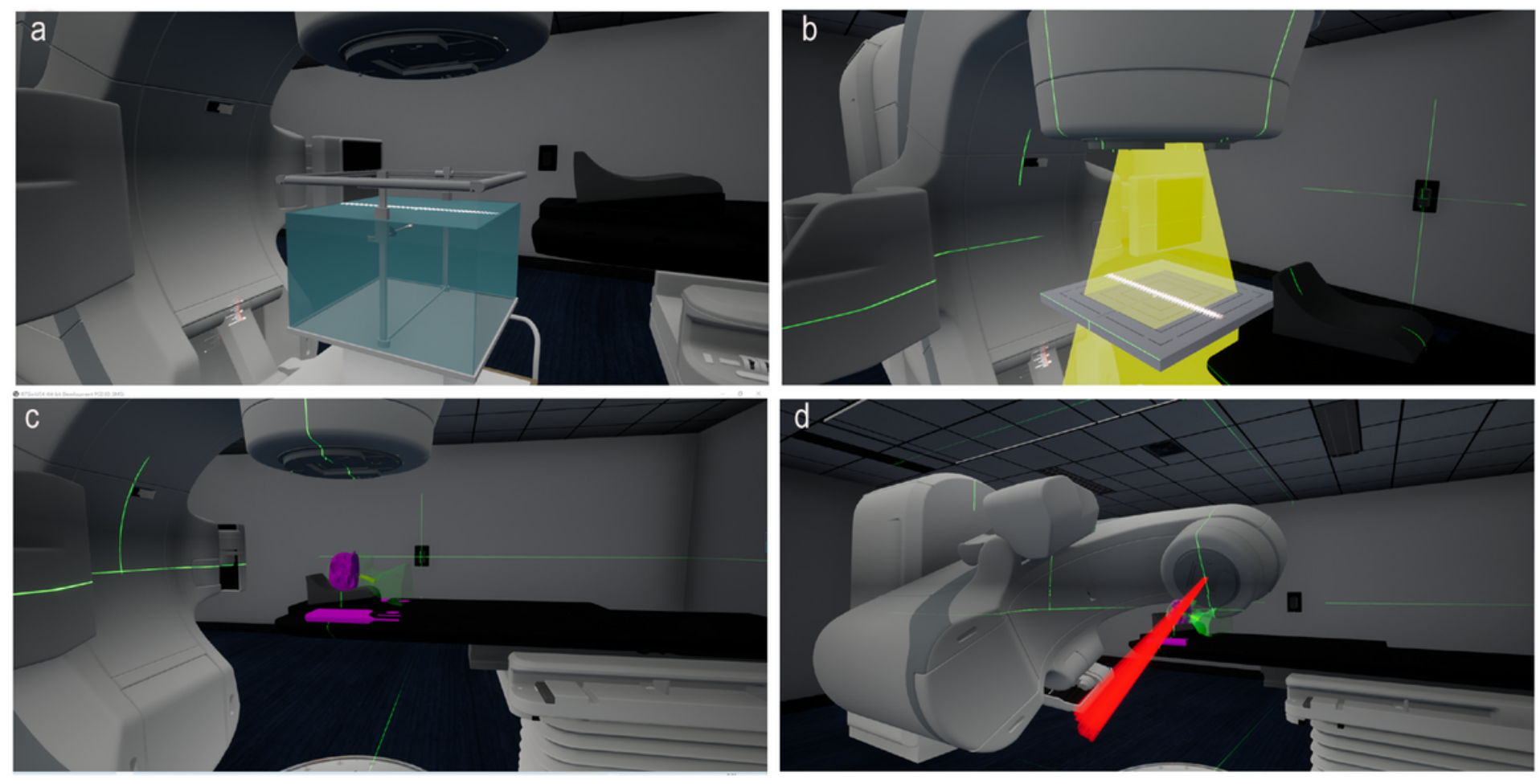

\section{Figure 3}

showed examples of screenshots from the "Linear accelerator simulation system" practical session in ChicaEducation system. The virtual water tank in ChicaEducation linear accelerator simulation system was displayed (Figure 3a), and it was used to create PDD plots. Multileaf collimators (MLCs) for the selected beam in ChicaEducation linear accelerator simulation system was shown in Figure 3b. ChicaEducation linear accelerator simulation system could monitor and calibrate the placement of radiotherapy. A sample of head and neck placement was displayed in Figure $3 c$, and Figure $3 \mathrm{~d}$ at different angles. 